\title{
EVOLUCIÓN CULTURAL Y LEGITIMIDAD EN LA COLOMBIA DE LA SEGUNDA MITAD DEL SIGLO XIX
}

\author{
Jorge Enrique González ${ }^{1}$ \\ Facultad de Ciencias Humanas ${ }^{2}$ \\ Universidad Nacional de Colombia
}

\section{Resumen}

En este artículo se examinan las circunstancias históricas de la Colombia de finales del siglo XIX tomando como punto de referencia la teoría de la evolución cultural expuesta por J. Habermas a propósito de su interés por las diversas formas que adopta la conciencia moral. Habermas propone una perspectiva evolucionista para tratar de elaborar un modelo teórico con el cual comprender las transformaciones lógicas, más que históricas, que sufre este fenómeno. De otra parte, se confronta el modelo de la evolución cultural con el estudio de los actores y movimientos sociales en lucha por la hegemonía de los modelos culturales, según A. Touraine, en este caso durante el periodo de la segunda mitad del siglo XIX colombiano, para lo cual se proponen los conceptos de cultura tradicional y cultura moderna.

\section{Palabras clave}

Colombia siglo XIX, evolución cultural, modelos culturales, movimientos sociales, actores sociales.

\section{Abstract}

In this article the historic circumstances of Colombia at the end or the XIX century are examined, takings into accent the theory of the cultural evolutions exposed by J. Habermas, in accordance to his interest for the diversified forms that the moral conscience adopts.

Doctor de la Universidad París X-Nanterre. Correo electrónico: jeg_1355@yahoo.fr.

2 Investigador del Centro de Estudios Sociales, CES, director del grupo Cultura y nación, profesor del Departamento de Sociología de la Universidad Nacional de Colombia. 
For this Habermas proposes an evolutive perspective trying to elaborate a theoretical model which will help in the comprehension of the logical transformations, more than historical, which this phenomenon takes. On the other hand, the model of the cultural evolution is confronted with the study with the actors and social movements in the struggle for the hegemony of the cultural models according to A Touraine, in this case during the period of the second hall of the XIX Combian Century, for which the concepts of the traditional culture and the modern cultures are proposed.

\section{Index terms}

Colombia XIX century, cultural evolution, cultural models, social movements, social actors.

Las notables transformaciones que vivieron las sociedades hispanoamericanas en el siglo XIX pueden ser interpretadas no sólo como el paso de un régimen político a otro, sino como un cambio de las formas de pensamiento, las cuales se adaptaron, aunque lentamente, a las necesidades de la modernización de las estructuras sociopolíticas y socioeconómicas. En este artículo examino la vigencia que puede tener la teoría de la evolución cultural de J. Habermas para comprender los procesos de modernización vividos en la Colombia del siglo XIX, para llegar a la formulación de una hipótesis acerca de la conformación de una manera laica (secular) de entender la cultura que habría entrado en contradicción con las formas tradicionales en que se expresaba en ese siglo la cultura fundamentada en el catolicismo, antes de producirse el aggiornamiento de la Iglesia Católica, para entender los problemas de la sociedad de finales de esa centuria.

\section{Potencial de aprendizaje en las sociedades}

El punto de partida en esta materia lo enuncia Habermas de la siguiente forma:
Parto de la idea de que las sociedades aprenden de modo evolutivo en la medida en que "incorporan institucionalmente” estructuras racionales que ya están caracterizadas en las tradiciones culturales, esto es: en la medida en que aprovechan la reorganización de los sistemas de acción. Tanto la empresa capitalista como la administración pública moderna o el derecho civil "incorporan" estructuras universales de conciencia. Desde este punto de vista, la raciona-lización de sistemas de acción tiene como consecuencia una ampliación de su capacidad de orientación, pero ello no implica un aumento en la complejidad del sistema. La racionalización de las estructuras de conciencia materializadas no se mide en relación con problemas sistémicos, sino en relación con tareas que, por medio del conocimiento objetivo y la percepción práctico-moral, resuelven unos sujetos capaces de pensar y actuar ${ }^{3}$.

Respecto de la teoría de la evolución de los sistemas sociales de Habermas, se requiere de algunas precisiones de orden metodológico, anunciadas por el propio autor. En primer término, no cabe concebir una teoría

3 Cf. HABERMAS, Jürgen. “Historia y evolución”. En: La reconstrucción del materialismo histórico. Madrid: Taurus, 1981, pp. 181-232. 
de este tipo como una síntesis universal de la historia de la humanidad en la que se obviarían los relatos y las narraciones específicas sobre las contingencias y circunstancias de un proceso histórico concreto. En ese sentido la teoría evolutiva se restringe a indicar una reconstrucción lógica del proceso, tomando como referentes los procesos concretos, pero tratando siempre de mantenerse en un alto nivel de abstracción que permita cobijar las diversas configuraciones. En segundo lugar, no se trata de utilizarla narrativamente, es decir, no se trata de convertirla en un "metarrelato" que determina de antemano las potencialidades del relato en sí mismo, porque esto, en términos de Habermas, reventaría el sistema referencial narrativo de la historiografía, para llevar a una “teorización de la historia." Pero esta disciplina no tiene por función en su desarrollo actual la elaboración de teorías, sino; más que todo, la aplicación o evaluación de teorías.

La concepción de Habermas respecto de las formaciones histórico-sociales comprende varios aspectos que pueden ser resumidos de la siguiente forma: a) se pueden caracterizar de acuerdo con la existencia de regulaciones muy abstractas a las que denomina "principios de organización”; b) entiende por principios de organización aquellas innovaciones producidas por medio de etapas de aprendizaje que se pueden reconstruir de modo lógico-evolutivo y que determinan un nivel nuevo de aprendizaje de la sociedad en cada $\mathrm{caso}^{4}$; c) un nivel de aprendizaje implica las condiciones estructurales que posibilitan procesos de aprendizaje técnico-cognoscitivo (racionalidad con arreglo a fines) y aprendi- zaje práctico-moral (racionalidad con arreglo a valores); d) el principio de organización de una sociedad determina los ámbitos de variación (de las fuerzas productivas, de los cambios del sistema institucional, de las tareas de orientación, es decir, el campo de variación de los sistemas de interpretación del mundo que garantizan la identidad); e) la transición de una formación social a otra representa un nuevo principio de organización que puede ser explicitado gracias a las evidencias institucionales.

Haciendo uso inicialmente de esta argumentación, con las ya anotadas precauciones de tipo metodológico, quisiera intentar una caracterización de los elementos históricos mas significativos de la Colombia del periodo de la Federación (1863-1886), para tratar de comprender los problemas de legitimación que se presentaron a lo largo del siglo XIX en Colombia, muy particularmente los que terminaron con el sistema federal de gobierno durante la década de 1880, momento en que se pone en evidencia el predominio de una orientación moral tradicionalista ${ }^{5}$.

Para iniciar, se requiere hacer una evaluación del tipo de organizador social que pudo haber primado en el periodo considerado. $\mathrm{Pa}-$ rece ser que se trataba de una fase de transición entre una formación social tradicional y algunos elementos sistémicos propios de una formación social capitalista liberal, porque elementos de estos dos tipos se encuentran entremezclados. En tanto que formación social tradicional, se puede registrar en la Colombia republicana del siglo XIX un esfuerzo continuo por diferenciar lo que Habermas denomina la integración social y

4 Habermas encontró justificado hablar de cuatro formaciones sociales básicas en la historia de la humanidad: la anterior a las altas culturas, la tradicional, la capitalista y la poscapitalista. Los principio de organización para las tres primeras serían correspondientemente así: i) los roles primarios de la edad y el sexo; ii) una sociedad de clase que posee forma política; iii) la relación entre trabajo asalariado y capital, enraizada en el derecho privado. Op. Cit., pp. 33-48.

5 Cf. GONZÁLEZ, Jorge Enrique. Positivismo y tradicionalismo en Colombia. Bogotá: El Búho, 1997. 
la integración sistémica. La primera hace referencia al desarrollo de prácticas y a la creación de instituciones en las que los sujetos hablantes y actuantes se socializan, lo que corresponde a la noción habermasiana de mundo-de-la-vida, en tanto que la integración sistémica se refiere a la capacidad de autogobierno de un sistema gracias al cual es capaz de reducir la complejidad del medio ambiente en el que tiene que actuar, manteniendo su identidad y su patrimonio.

La manera como se expresa el principio organizador de una sociedad tradicional tiene que ver, según Habermas, con la diferenciación funcional entre segmentos especializados de la sociedad, que en el plano político corresponden en la experiencia histórica de Occidente a las concepciones modernas de la organización del Estado y particularmente a la división tripartita del poder público, fenómeno que conlleva la separación entre la jurisdicción y potestad del poder civil frente a otras opciones, en especial frente al poder de los religiosos.

Al respecto el autor antes citado señala lo siguiente:

En su punto de articulación se encuentra el aparato jurídico, que regula la facultad de disposición privilegiada sobre los medios de producción y el ejercicio estratégico del poder, que a su vez necesita de legitimación. A la diferenciación entre aparato de poder y régimen jurídico, por un lado, y justificaciones contrafácticas y sistemas morales, por el otro, corresponde la separación institucional entre autoridades seculares y sagradas. El nuevo principio de organización permite un significativo incremento de la autonomía sistémica, presupone una diferen- ciación funcional y posibilita la creación de "medios" generalizados (poder y moneda), así como de mecanismos reflexivos (derecho positivo) 6

Por otra parte, los elementos de la formación social capitalista liberal que aparecieron en nuestro medio fueron fragmentarios, ya que a lo largo del siglo XIX no se logró desarrollar de manera suficiente el aspecto cognitivo-instrumental necesario para potenciar de manera notable las fuerzas productivas, de tal forma que llegara a convertirse en un elemento sistémico determinante. No obstante, la preocupación por desarrollar las fuerzas productivas a la manera de las principales formaciones sociales europeas o americanas se constituyó en una constante a partir de las reformas de medio siglo, en particular durante los gobiernos del periodo de la Federación con su interés en el desarrollo de las vías de comunicación y el fortalecimiento del mercado nacional, contando además con los antecedentes importantes de las reformas intentadas en las administraciones de Pedro Alcántara Herrán (1841-1845) y Tomás Cipriano de Mosquera (1845-1849).

A pesar de que esos esfuerzos no fueron suficientes para lograr una reorganización sistémica, sí se lograron algunas transformaciones estructurales, especialmente en el plano político-administrativo, continuando con la secuencia ya inaugurada en la gesta emancipadora, en la que se modificaron las estructuras políticas y administrativas sin que se produjera una transformación concomitante en las estructuras socioeconómicas.

Los rasgos de un nuevo orden social en el plano señalado se perciben en las funciones asignadas al aparato de Estado en la Colombia de la época, que, siguiendo la imagen

6 HABERMAS, J. Problemas de legitimación en el capitalismo tardío. Buenos Aires: Amorrortu, 1975, p. 36. 
proyectada por los países europeos y americanos de mayor desarrollo en el sentido antes anotado, se adoptaron en nuestro medio, en cuanto a la adaptación de las estructuras burocráticas propias del régimen colonial español a una orientación de tipo republicano, en la que el principio de la soberanía popular y la incorporación de los Derechos del hombre y del ciudadano a los fundamentos del orden jurídico racional legal se constituyen en algunos de sus rasgos más característicos. Así, por ejemplo, el deseo de seguir la senda de formaciones sociales ya desarrolladas llevó a que se intentara una adaptación precaria para nuestras condiciones de: i) los aspectos técnico-cognoscitivos, ii) los aspectos práctico-morales, y iii) las tareas de orientación. Se lograron transitoriamente algunas transformaciones a nivel de las estructuras normativas, en el sentido de proponer criterios de tipo utilitarista (siguiendo la influencia de las doctrinas de J. Bentham) y estratégicos para fundamentar las relaciones interpersonales y las reglas del mercado, pero sin contar con una transformación correlativa de las fuerzas modeladoras de una economía de mercado.

Quizá sea esa la razón que nos ayude a comprender por qué en la circunstancia histórica de la década de 1870, cuando se precipita una crisis económica local a raíz de la baja del precio del tabaco en los mercados internacionales, que conllevó a un fuerte desequilibrio de las finanzas públicas, no fuera ese el principal elemento para agudizar la confrontación partidista. El elemento determinante lo constituyó la crisis en cuanto a los problemas de identidad nacional, expresados en el plano político por las fuertes críticas al supuesto efecto deletéreo del régimen federal; en el plano moral, el principal indicador de la crisis consistió en los severos cuestionamientos a las doctrinas utilitaristas y positivistas que se querían propagar a toda la población, especialmente a través de un sistema educativo secularizado.

Estos argumentos me permiten señalar que la mezcla indeterminada entre elementos de un orden social tradicional y el capitalismo liberal no permitió establecer una clara transición hacia un nuevo principio organizador que superase al previamente vigente. Para las necesidades de legitimación esto significó que los asuntos relacionados con la propensión a conservar los patrones de identidad de una sociedad tradicional no podían ser modificados sin propiciar una crisis social por la aguda confrontación en torno al modelo cultural (católico-tradicionalista) imperante.

Otra forma de examinar este problema consiste en explorar las propiedades formales que, según Habermas, deben poseer los modelos culturales para que en el mundo de la vida sean posibles las orientaciones racionales de la acción y éstas se expresen en un modo de vida racional ${ }^{7}$. Considera este autor que son básicamente cuatro las condiciones formales, a saber:

a) El modelo cultural debe poner a disposición de los actores los conceptos formales de mundo objetivo, mundo social y mundo subjetivo; debe permitir pretensiones de validez diferenciadas (verdad proposicional, rectitud normativa, veracidad subjetiva) e incitar a la correspondiente diferenciación de actitudes básicas (objetivante, de conformidad/no conformidad con las normas, y expresiva). Sólo entonces pueden generarse manifestaciones simbólicas a un nivel formal en

7 El concepto de racionalidad nos remite en Habermas a la capacidad comunicativa de los seres humanos para llegar a acuerdos no coactivos, por medio de los cuales dirigir su actividad. 
que pueden quedar sistemáticamente conectadas con razones y ser accesibles a un enjuiciamiento objetivo.

b) El modelo cultural debe permitir una relación reflexiva consigo mismo; debe despojarse de su dogmática hasta el punto en que las interpretaciones nutridas por la tradición puedan quedar puestas en cuestión y ser sometidas a una revisión crítica. Sólo entonces los nexos de sentido pueden ser objeto de una elaboración sistemática y pueden estudiarse metódicamente interpretaciones alternativas. Aparecen entonces actividades cognitivas de segundo orden: procesos de aprendizaje guiados por hipótesis y filtrados argumentativamente, en estos ámbitos: i) del pensamiento objetivante, ii) de las ideas práctico-morales, y iii) de la percepción estética.

c) El modelo cultural debe permitir, en lo que concierne a los componentes cognitivos y evaluativos, una conexión de retroalimentación con formas especializadas de argumentación hasta el punto de que los correspondientes procesos de aprendizaje se puedan institucionalizar socialmente. Por esta vía surgen sistemas culturales especializados, respectivamente en: i) ciencia, ii) moral y derecho, iii) arte y literatura; en ellos se forman tradiciones sostenidas argumentativamente, dinamizadas por una crítica permanente que debe ser estudiada a partir del segui- miento de la actividad de actores sociales específicos que pugnan por la preponderancia de sus modelos culturales y a la vez aseguradas por la profesionalización que generan.

d) El modelo cultural debe, finalmente, permitir interpretar el mundo de la vida en donde se escenifica la confrontación entre los diversos actores colectivos y sus modelos culturales, de modo que la acción orientada al éxito quede exenta de los imperativos a que la supeditaría un entendimiento que fuera menester renovar comunicativamente de forma incesante, y quede desconectada, al menos parcialmente, de la acción orientada al entendimiento. Con ello resulta posible la institucionalización social de la acción "racional con arreglo a fines” para fines generalizados, como, por ejemplo, la formación de subsistemas de acción económica y de la administración racional, regidos, respectivamente, por los medios dinero y poder ${ }^{8}$.

Respecto de este último aspecto anotado en el literal d), diversos críticos de la obra de Habermas han objetado que se estaría legitimando la existencia de una esfera del mundo de la vida, cediendo a imperativos sistémicos gobernados por la acción racional con arreglo a fines que sólo en forma parcial se podrían someter a control crítico. En sus obras más recientes Habermas se refiere en particular al medio poder, tema-

8 Cf. HABERMAS, J. Perfiles filosófico-políticos. Madrid: Taurus, 1975, p. 205-206. En ese orden de ideas, se reserva la posibilidad de introducir una concepción dialógica y no coactiva del concepto de poder, aunque queda por precisar la forma como se articula la instancia coactiva con la no coactiva. Desde otra perspectiva,. E. Serrano cuestiona en forma abierta el legado funcionalista de la teoría de T. Parsons en relación con la función del poder en las sociedades modernas, pues, según Serrano, en la concepción de Habermas se ve una vez más la toma de posición a favor de Parsons, aunque aclara que Habermas no asume ciertas premisas idealistas de la teoría de la sociedad de Parsons y se atiene al primado de la teoría de la acción, precisamente el plano desde el cual invoca Serrano la necesidad de conocer en detalle las confrontaciones entre grupos concretos de la sociedad por el monopolio del poder y por las ideologías legitimantes. Cf. SERRANO, E. Legitimación y racionalización. México: Anthropos-UAM, 1994, pp. 247-257. 
tizando lo correspondiente a las expresiones jurídicas que reviste el poder y proponiendo la estrategia de la racionalidad procedimental. Es necesario tomar en cuenta el concepto de poder que propone Habermas, explicitado por ejemplo en la reseña que hizo de la obra de Hanna Arendt ${ }^{9}$, en donde establece la distinción entre los conceptos germánicos de Macht y Gewalt; en tanto que el primero lo remite a la acepción utilizada por Max Weber para designar la capacidad de disponer de los medios para influir sobre la voluntad de los otros, el segundo lo encuentra utilizado en los trabajos de H. Arendt para diferenciar el uso de la coacción física, es decir la fuerza, la violencia, el poder instrumental, según dice Habermas. Él se propone conservar para el concepto de Macht la movilización del asentimiento de los miembros de una comunidad para los fines de una colectividad, es decir — anota Habermas_- la disponibilidad de los miembros de la acción política; mientras que Gewelt significaría el disponer de recursos y de medios de coacción en virtud de los cuales una dirección política puede tomar e imponer decisiones vinculantes para realizar los fines colectivos.

Para los efectos que aquí nos interesan quisiera destacar que el proceso histórico por medio del cual las tradiciones culturales de Occidente en la época moderna conservan un tono semejante, conduce a preguntar por las razones estructurales que permiten que unos patrones se actualicen en diferentes contextos concretos y, sobre todo, tratar de precisar de dónde provienen sus notables diferencias. En su interpretación de la modernización cultural, Max Weber establece que el desencantamiento de las imágenes religiosas del mundo permite la separación funcional entre tres esferas de acción, a saber, la ciencia, el arte y la moral. Esta diferencia- ción la caracteriza Weber por el peso abrumador que tiene desde el subsistema económico la racionalidad con arreglo a fines que presiona los cambios en las otras esferas. Sin embargo, Habermas encuentra insatisfactorio este diagnóstico del desencantamiento del mundo y propone considerar como forma de racionalización que sirve de "recipiente” para las transformaciones posteriores a las mismísimas imágenes religiosas del mundo. En su concepto, el análisis weberiano pasa por alto las maneras como esas imágenes sirven de fundamento para desarrollar versiones alternativas que marcarían el paso a la modernización cultural. En otros términos, considera que no fue exclusivamente el peso de la racionalidad con arreglo a fines lo que marcó el paso a la modernización cultural, sino que se interesa por recoger los aspectos de transición entre un sistema y otro, para lo cual resulta indispensable establecer un modelo teórico en el que se dé cabida a las realizaciones fragmentarias.

Al respecto se pregunta Habermas lo siguiente: ¿Qué transformaciones tuvieron que producirse en las estructuras del mundo de la vida de las sociedades tradicionales antes de que el potencial cognoscitivo surgido de la racionalización religiosa pudiera utilizarse socialmente y materializarse en los órdenes de la vida estructuralmente diferenciados de una sociedad que queda modernizada precisamente por esta vía? Quisiera retomar los términos de este interrogante para tratar de establecer las relaciones entre un modelo cultural católico y otro laico, puesto que en la circunstancia histórica de la Colombia del siglo XIX, estos dos aspectos resultaron ser los elementos de referencia en la confrontación entre cosmovisiones y entre esfuerzos por avanzar en la modernización de nuestra formación social.

9 HABERMAS, J. “Hanna Arendt”. En: Perfiles filosófico-políticos. Madrid: Taurus, p. 206. 


\section{Cultura tradicional y cultura moderna}

Uno de los aspectos más significativos de los estudios sobre la cultura en América Latina puede estar representado en el interrogante que suscita la real o aparente inmovilidad de algunas de sus estructuras ideológicas profundas o, para decirlo en otros términos, la persistencia de un determinado tipo de mentalidad.

Frente a este interrogante podemos encontrar dos vertientes: de una parte quienes consideran que las grandes estructuras simbólicas que conforman nuestra cultura han sido objeto de una notoria discontinuidad, en especial, desde las postrimerías del siglo XVIII cuando la penetración de las ideas ilustradas logra transformar el "ritmo eterno" del régimen colonial y propone un nuevo esquema de interacción del hombre con la naturaleza, en el que la identidad del hombre moderno se va a encontrar en permanente transformación. De otra parte encontramos a quienes sostienen que la historia de Latinoamérica, y en particular de sus manifestaciones culturales, se comprende a partir de sus continuidades más que de sus rupturas, es decir que lo que predomina es una cierta tradición cultural más que la presencia de una dinámica de rupturas ${ }^{10}$.

Este problema de la continuidad o ruptura del universo cultural latinoamericano nos conecta con un elemento concomitante que tiene íntima relación con la formación social en su conjunto. Si bien es cierto que una ge- neralización simplista nos conduciría a desconocer las enormes diferencias que existen entre las naciones latinoamericanas, así como en las regiones internas de cada nación, no por ello podemos abandonar la posibilidad de encontrar algunos elementos estructurales que ayuden a comprender las particularidades. En ese orden de ideas podemos establecer que en la sociedad tradicional, que en nuestro caso corresponde al periodo colonial y a buena parte del periodo republicano, quizá hasta la primera mitad del siglo XX, el principio de identidad más sólido se encuentra fundamentado en una cosmovisión católica ${ }^{11}$, a un grado tal que podemos entenderla efectivamente como una cultura tradicional católica, si nos atenemos a la concepción expresada por G. W. F. Hegel, según la cual la religión puede ser entendida como el concepto que un pueblo tiene de sí mismo. Debe hacerse la salvedad de que el planteamiento hegeliano se refiere al nivel de desarrollo de una sociedad tradicional, como se observará por los referentes históricos que utiliza, y en ese sentido algunas de sus admoniciones enciclopédicas no tendrían validez transhistórica.

No obstante, las observaciones a propósito del papel de la religión en la sociedad tradicional, y muy particularmente las referencias a la religión católica, nos permitirán la caracterización de aquello que conceptualmente propongo denominar como una cultura tradicional. Hegel califica como "el gran error de nuestro tiempo" (comienzos del siglo XIX) el querer considerar como diferentes a la religión y al Estado, puesto que éste se

10 Esa es, por ejemplo, la posición del historiador venezolano Mariano Picón Salas, quien plantea que "la historia cultural hispanoamericana no obedece tanto a una tradición de la ruptura, sino a una tradición sin más; esa continuidad es la condición necesaria para emprender una historia del alma criolla”. PICÓN SALAS., M.. De la conquista a la independencia. Caracas: Monte Ávila, 1978, p. 227.

11 Entendida en el sentido que la propone Mircea Eliade: la religión establece un cosmos sagrado. ELIADE, M. Mito y realidad. Barcelona: Guadarrama, 1973, pp. 181-192. 
fundamentaría en la “disposición de ánimo ética, y ésta en la religiosidad” ${ }^{12}$. Sin embargo es consciente de que ya para su época se presentan síntomas de separación entre estos, los que describe de la siguiente manera:

Así la relación de la religión con el Estado ha sido considerada de este modo: que el Estado existe ya por sí y por una fuerza y poder cualquiera, y la religiosidad, como cosa subjetiva de los individuos, debe añadírsele sólo para reforzarlo, tomándola casi como algo deseable, o también indiferente, y la eticidad del Estado, esto es, el derecho racional y la Constitución, se mantiene firme por sí en su propio fundamento ${ }^{13}$.

También contempla los síntomas que se presentan en el caso de la religión:

Concierne primero a la forma, esto es, a la autoconciencia con el contenido de la verdad. Como éste es la sustancia como espíritu de la autoconciencia incidente en la realidad, la autoconciencia tiene la certidumbre de sí misma en este contenido y es libre en él. Pero la relación de la servidumbre puede tener lugar según la for- ma, aunque el contenido en sí de la religión sea el espíritu absoluto ${ }^{14}$.

Lo que resulta más sugestivo para el tema que nos ocupa, en el sentido de caracterizar la cultura católica, es que Hegel elabora una argumentación valiosa acerca de la diferencia que se encuentra en la religión católica respecto al cristianismo, porque, en su criterio, se presenta una variación en cuanto a la relación entre contenido y forma: en el cristianismo primitivo el contenido estuvo representado por la idea de Dios como espíritu, sin necesidad de acceder a una serie de materializaciones que lo representaran.

Para la cultura tradicional católica, que es en gran medida una cultura eclesiástica en el sentido propuesto por Ernest Troeltsch, es decir, aquella que reposa en la creencia en una revelación divina, absoluta y directa, así como en la organización administrativa de la revelación en un instituto de salvación y de educación que es la Iglesia, cuya característica distintiva es el de un profundo autoritarismo ${ }^{15}$, el orden espiritual se presenta en la realidad en formas materiales exteriores; por ejemplo, según Hegel, Dios es presentado a la adoración religiosa como una cosa externa (la hostia) ${ }^{16}$.

12 Hegel distingue entre contenido y forma de la relación entre religión y Estado, así: “Las dos cosas son inseparables; no puede haber dos diversas conciencias, una religiosa y otra ética que sea diversa de aquella por el contenido. Pero, según la forma, esto es, por el pensamiento y por el saber, religión y eticidad pertenecen a la inteligencia y son un pensamiento y un saber -corresponde al contenido religioso, como verdad pura y que es en sí y para sí, y, por consiguiente, suma verdad, sancionar la eticidad, que está en la realidad empírica; así la religión es por la autoconciencia la base de la eticidad y del Estado”. G.W.F. Hegel, Enciclopedia de las ciencias filosóficas. México: Porrúa, 1973, p. 284.

13 Ibídem.

14 Ibídem.

15 Sobre los aspectos del autoritarismo de la religión dice Troeltsch: "Se trata, por lo tanto, de una cultura autoritaria en grado máximo, que despierta, con su autoridad, las aspiraciones más altas por la salvación eterna y las más vivas profundidades de la vida subjetiva del alma, y que traba lo divino inmutable y lo humano mudable en un cosmos de ordenadas funciones culturales”. TROELTSCH, Ernest. El protestantismo y el mundo moderno. México: F.C.E., 1951, p. 15.

16 Al respecto vale mencionar los análisis críticos de J. E. Caro acerca de la preponderancia del culto externo en detrimento de los aspectos centrales del dogma: "La Nueva Granada, durante el pupilaje colonial, no conoció doctrina moral alguna que fuese enseñada, porque en aquella época de sueño nada se enseñaba. 
De esa primera y fundamental exterioridad considera Hegel que se derivan todas las demás manifestaciones externas de adoración en el culto católico, las que él considera como no libres, no espirituales y supersticiosas. Las consecuencias no pueden ser más delicadas: todo esto sujeta el espíritu a una exterioridad, por lo que su esencia es desconocida en su intimidad y es extraviada; en consecuencia el derecho, la justicia, la moralidad, la conciencia, la responsabilidad y el deber son dañados en su raíz. A dicho principio y a este desarrollo de la servidumbre del espíritu en el dominio religioso, corresponde, según Hegel, una legislación y constitución de la servidumbre jurídica y ética, y una condición de injusticia e inmoralidad en el estado real de la vida cotidiana.

Consiguientemente, dice Hegel, la religión católica ha sido y es aún con frecuencia altamente valorada como aquella por la cual es asegurada la estabilidad de los gobiernos; pero, efectivamente, de aquellos gobiernos ligados a instituciones que se fundan en la servidumbre del espíritu -el cual debería ser jurídicamente y éticamente libre-, esto es, bajo instituciones de la injusticia y bajo una condición de corruptela y de barbarie moral ${ }^{17}$.
En concepto de Hegel este principio de la servidumbre, hegemónico en la vida religiosa, impide el desarrollo de una reflexión racional como es la filosofía, particularmente la reflexión sobre la moral secular ${ }^{18}$, puesto que el contenido moral se asimila a una "cosa santa”. El desarrollo de la reflexión humana viene a transformar ese orden de cosas, y lo que antes era considerado como santidad viene a ser sustituido por la eticidad, y lo que antes se acataba por obediencia o subordinación puede ser transformado por la obediencia a la ley y a las instituciones legales del Estado. Al ponerse en evidencia la necesidad del derecho y la eticidad para garantizar la convivencia humana, junto con el conocimiento que la razón humana tiene de la naturaleza, surge la lucha de la razón contra la religión de servidumbre.

La conclusión de Hegel respecto a la coexistencia de estos dos niveles de la realidad es tajante: los dos son incompatibles entre sí porque no sirve que las leyes y el ordenamiento del Estado se transformen en organización jurídica racional si no se abandona en la religión el principio de la servidumbre: "Es sólo una idea abstracta y vacía imaginarse como posible que los individuos obren

La religión sólo la conocimos por sus prácticas, por su culto externo, por la parte de ella que más se dirige a los sentidos; no por el dogma, no por la fe, no por la caridad, no por la parte sublime de ella que se dirige al corazón y al alma. Sin duda el culto externo hace parte integrante del cristianismo, pero en modo alguno es su parte principal”. CARO, José E. “Al Sr. Joaquín Mosquera, sobre el principio utilitario enseñado como teoría moral en nuestros colegios, y su relación que hay entre las doctrinas y las costumbres”. La civilización, 20, 1849, p. 81.

17 HEGEL, G. W. F. Op. Cit., p. 285.

18 Es importante anotar aquí la percepción contemporánea de este asunto, por ejemplo en la formulación que hace Habermas: "Pero el pensamiento filosófico se ve confrontado hoy no sólo con la consolidación de una conciencia tecnocrática, sino también con la desintegración de la conciencia religiosa. Hoy por primera vez queda patente que la interpretación filosófica del mundo, con sus restricciones elitistas, necesitaba de la coexistencia con una religión que incluyera bajo su influencia a la mayor parte de la población. Pues la filosofía aún después de haber asumido los impulsos utópicos de la tradición judeo-cristiana, se ha mostrado incapaz de obviar (¿o de dominar?) por medio del consuelo y la esperanza el sin sentido fáctico de la contingencia de la muerte, del sufrimiento individual y de la pérdida de la felicidad y, en general, la negatividad de los riesgos que acechan a la existencia individual, con el mismo suceso con que lo hizo la esperanza religiosa en la salvación”. HABERMAS, J. Perfiles filosófico-políticos. Madrid: Taurus, 1975, p. 33. 
sólo según el sentido o la letra de la legislación, y no según el espíritu de su religión, en que consiste su íntima conciencia y su suma obligación”. Más adelante añade: “Es de estimar como nada más que una locura de los tiempos modernos cambiar un sistema de costumbres corrompido y la constitución del Estado y la legislación sin cambiar la religión, sin haber hecho una reforma”. Y concluye así: "Es la suma más profana de las contradicciones que se pueda concebir, querer ligar y supeditar la conciencia religiosa a la legislación mundana que ella considera como profana”"19.

Las implicaciones que tiene una cultura tradicional católica para la legitimación de un sistema político son inmensas, porque es la conciencia religiosa la que permite derivar el principio de acatamiento a las normas; si esto no ocurre así, se pone en evidencia la contradicción existente entre estos dos órdenes y se precipita la confrontación. Este fenómeno se presenta históricamente a diferentes niveles, pero su operatividad se registra como una constante que adopta la fuerza de un principio regulador del orden social tradicional.

Ha sido Peter Berger quien nos recuerda la existencia de diversos niveles en los que opera la legitimación por vía de las creencias religiosas, cuando plantea la existencia de una facticidad legitimadora y la de las legitimaciones secundarias. En cuanto a la primera, hace referencia al orden objetivo de la realidad social que adquiere y le es reconocido por los hombres un recto sentido. Pero en cuanto surgen dudas o dificultades con este nivel de facticidad, aparecen las legitimaciones secundarias, que, según
Berger, contienen varios matices, así : 1) un nivel preteórico compuesto por afirmaciones que salvaguardan la forma tradicional de hacer las cosas, 2) un nivel teórico incipiente que corresponde al nivel de elaboración de un saber popular en forma de mitos, cuentos o leyendas, para llegar a 3) un tercer nivel en el que se establecen legitimaciones teóricas complejas, de las cuales forman parte las religiones ${ }^{20}$.

Ahora bien, podemos considerar al derecho natural subsumido en la cultura tradicional católica como una de las legitimaciones complejas a las cuales se hizo referencia, entendido como un mecanismo social en el que se mantiene en equilibrio la tensión que surge entre la capacidad para regular los conflictos y la instrumentalidad del derecho cuando se pone al servicio de un aparato de dominación. Al respecto anota Habermas que “esta tensión se mantiene en equilibrio mientras no se ataque el fundamento sacro del derecho y mientras la base del derecho consuetudinario que es afianzado por la tradición, permanezca firmemente anclado en la praxis cotidiana”21.

\subsection{Transformaciones del modelo cultural tradicional católico}

A continuación paso a reconstruir las vías por las que una cultura tradicional católica se empieza a descomponer para dar lugar a algunos síntomas de transformación. Para esto avanzaremos en una doble dirección, de una parte examinando la conceptualización de los procesos de modernización y secularización, de otro lado precisando el concepto de cultura moderna.

19 HEGEL, G. W. F.. Op. Cit., p. 286.

20 BERGER, Peter. El dosel sagrado. Buenos Aires: Amorrortu, 1971, pp. 44-46.

21 HABERMAS, J. “Derecho y moral (dos lecciones)”. En: El derecho, la política y la ética. Comp., David Sobrevilla. México: Siglo XXI/UNAM, 1991, p. 57. 
Iniciemos con los procesos de modernización y secularización. En el caso colombiano podemos comenzar señalando que los primeros elementos de una ideología modernizadora se presentaron en la elite criolla neogranadina de la segunda mitad del siglo XVIII. Antes de continuar, es conveniente precisar aquí que modernización hace referencia al control creciente y al desarrollo de las condiciones materiales de una sociedad, para diferenciarlo de la modernidad, entendida ésta como el proceso de desencantamiento del mundo, en el sentido en que lo expresa M. Weber y, a partir de éste, entre otros, J. Habermas, proceso que comporta una decisiva secularización del mundo de la vida en tanto que se trata de pasar de un orden recibido a un orden producido ${ }^{22}$.

Con respecto a la manera como se ha interpretado en nuestro medio el proceso de modernización y el ingreso a la modernidad en la Colombia del siglo XIX, es necesario señalar que se mantiene una escisión marcada entre los aspectos materiales y los factores intelectuales. Esto recuerda la clásica distinción entre los conceptos de civilización y de cultura. El primero, de origen francés, denota el poder natural, los elementos materiales de la existencia, en tanto que el segundo, de origen alemán (Kultur), se reserva para designar el progreso intelectual y científico. ${ }^{23}$ En ese orden de ideas se fundamentan las recientes formulaciones de varios autores colombianos que destacan el papel de los elemento materiales (económicos) y morfológicos (sociales) en el proceso de modernización del país.

Así, por ejemplo, para J. O. Melo los principales indicadores de la modernización en el siglo XIX se originan en la situación de finales del siglo XVIII. En su concepto, en el plano económico los factores serían la exportación de metales preciosos, producción agrícola para el autoconsumo, mano de obra ligada al régimen de las haciendas, existencia de mercados locales mas no nacionales, debilitamiento de la importancia económica de los esclavos y los indígenas, tasas de cre-

22 Al respecto Habermas nos habla del modernismo como una "profanización de la cultura”: "El modernismo es básicamente un proceso de profanizacion de la cultura; todas las categorías de la vida cotidiana se hacen profanas, manipulables, al alcance de cualquiera, tal como en la mentalidad protestante se hizo profana la Biblia al ser entregada a cada creyente para su lectura, desterrando de paso el analfabetismo. Dos conceptos más sociológicamente relacionados, desarrollo de la libre empresa y formación de un Estado de carácter burocrático, le darían a la modernización la fisonomía de una estructura social bajo el imperio de un criterio de racionalización de corte instrumental, como una especie de infraestructura de la cultura moderna, pero que rápidamente se muestra como la estructura del capitalismo”. HABERMAS, J. El discurso filosófico de la modernidad. Madrid: Taurus, 1989, pp. 11-12.

23 Fernand Braudel indica que "desde Herder, la lengua alemana designa bajo el término de cultura al progreso intelectual y científico, al que se muestra inclinada a separar de todo contexto social; entiende preferentemente por civilización tan sólo el aspecto material de la vida de los hombres”. BRAUDEL, F. La historia y las ciencias sociales. Madrid: Alianza, 1974, p. 138. También Michel Despland argumenta sobre esta distinción, en una perspectiva histórica: “A la defensiva, Alemania reivindica como suya la cultura y le da un sabor de interioridad profunda que escapa a la mirada de los extranjeros. Ese discurso ignora los aspectos políticos: la cultura es el amor propio de una clase separada de toda actividad política. Ese discurso permite formular la gran reivindicación en contra de los franceses, de la que la conciencia nacional germana tenía necesidad luego de la época de las luces y de la epopeya napoleónica, la reivindicación de un estado de desarrollo espiritual superior y sin comparación al subdesarrollo social y político”. DESPLAND, M. "La notion moderne de culture". En: Religion et culture. Por DESPLAND, M., et. al. Quebec: PULEditions du Cerf, 1986, p. 228. (Trad. mía). También N. Elias argumenta en un sentido semejante en "Sociogénesis de los conceptos de civilización y cultura”. En: El proceso de la civilización. México: F.C.E., 1997. 
cimiento económico superiores a los del aumento de la población; como factores sociales (morfológicos) atiende a los siguientes: territorio fragmentado regionalmente, sistema limitado de transporte, alto porcentaje de la población que habla el mismo idioma, rápido proceso de mestizaje, crecimiento de la población relativamente rápido (1,5\% anual), sistema legal, tributario y monetario relativamente uniforme ${ }^{24}$.

Este enfoque, que se ha logrado ubicar como el principal modelo de interpretación historiográfico de ese proceso, deja de lado el papel de los elementos de carácter intelectual que en no pocas ocasiones se ponen de presente de una manera muy destacada, al grado de convertirse en aspectos claves, 0 , tal vez, determinantes de los procesos históricos. En ese sentido resulta difícil aceptar el modelo de interpretación propuesto en los trabajos de Melo, de amplia aceptación en los círculos académicos colombianos, según el cual en el siglo XIX se habría creado un amplio consenso en todos los sectores de la elite en torno a que el objetivo de la independencia nacional debía ser el establecimiento de una economía capitalista y un sistema político basado en la soberanía popular, a un punto tal, dice Melo, que "los objetivos del proyecto modernizador no se vieron alterados sustancialmente por las vicisitudes de las luchas políticas del siglo XIX”25.

En nuestro concepto, el panorama fue muy diferente, puesto que aun aceptando que existieron elementos semejantes para definir el proyecto modernizador, en el sentido de vincularnos a la historia universal al estilo occi- dental, las controversias en torno a las concepciones humanísticas sí marcaron de una forma decisiva el ritmo y la dirección de ese proceso.

En ese sentido la vinculación con las corrientes de pensamiento y las cosmovisiones asociadas a la modernidad representó para las elites dirigentes un tema que las separó hasta convertirse en dos opciones irreconciliables, que si bien se mantuvieron cohesionadas frente a algunos temas vitales de la organización política del Estado republicano y de manera retórica frente a las teorías de la soberanía popular, no lo estuvieron en torno a la fundamentación de la actividad política y jurídica, por cuanto se distanciaron en forma radical por sus diferentes concepciones. En ese orden de ideas se puede encontrar que en un periodo de larga duración, como puede ser el caso del tránsito del régimen colonial a las postrimerías del siglo XIX, se observa un fragmentario proceso modernizador, pero no podría decirse que éste va acompañado de un proceso satisfactorio en cuanto a la adopción de una mentalidad de tipo moderno que lo sustente.

Al respecto tendríamos que preguntarnos si los elementos modernizantes que pudo contener la mentalidad católica, según lo expresado por Habermas, contribuyeron en ese periodo a adoptar elementos estructurales de la racionalidad moderna o si, por el contrario, esa mentalidad fue completamente refractaria a esas innovaciones. Quizá sea por eso que suele hablarse de una modernización incompleta, escindida, postergada, o trunca, para denotar que tanto en el plano de la modernización, como en el ingreso a la moder-

24 MELO, J. O. “Proceso de modernización en Colombia, 1850-1939”. Revista de extensión cultural (Universidad Nacional, sede Medellín), No. 20, 1985, p. 33.

25 MELO, J. O. “Algunas consideraciones globales sobre modernización y modernidad”. En: Colombia, el despertar de la modernidad. Por VIVIESCAS, F. y GIRALDO, F. 2a. ed. Bogotá: Ediciones Foro por Colombia, 1994, p. 232. 
nidad, el nuestro ha sido un proyecto sui generis en donde, por ejemplo, se asistía al final del siglo XIX a una fórmula tan particular como la de una modernización tradicionalista.

\subsection{Cultura moderna}

El concepto de cultura moderna nos aproxima a una de las dimensiones que queremos subrayar de la modernidad, en el sentido de que esa nueva mentalidad presupone una constante liberación del modo de ser del hombre respecto de las ataduras impuestas por la cosmovisión religiosa, en este caso católica. El concepto de cultura moderna nos aproxima también al "desencantamiento del mundo," al terreno de un mundo en el que la unidad de los discursos teológicos y metafísicos es sustituida por el "politeísmo de los valores”, produciéndose una diferenciación entre tres esferas de valor relativamente autónomas, como son la ciencia, la moral y el arte, que deben producir sus propias argumentaciones y fundamentaciones.

De una manera más precisa, la cultura contemporánea describe el rasgo que E. Troeltsch identifica como la naturaleza de la cultura moderna, a pesar de que la secularización se constituye en una visión recortada de la modernidad en cuanto que no logra desarrollar todo el potencial liberador del hombre y se convierte en un sistema cerrado que en varios aspectos viene a funcionar como la nueva religión de una elite que se considera portadora de la Razón:

Significa, en general, la lucha en contra de la cultura eclesiástica y su sustitución por ideas culturales autónomamente engendradas, cuya validez es consecuencia de su fuerza persuasiva, de su inmanente y directa capacidad de impresionar. Fúndese como se funde, todo lo domina la autonomía frente a la autoridad eclesiástica, frente a las normas divinas y puramente exteriores ${ }^{26}$.

No obstante, es necesario reconocer que, aunque restringida a una elite que la convierte en una nueva ideología, esa concepción de la cultura sirvió de soporte para la conformación de un movimiento social transformador de los modelos de historicidad imperantes en momentos y lugares determinados, que dio como resultado la formación de los Estados nacionales contemporáneos. Ha sido precisamente A. Touraine quien ha destacado la importancia de los elementos ideológicos, o intelectuales, en la conformación de los movimientos sociales, entendiendo que son estos movimientos los que se encargan de producir la historia humana. Al respecto señala:

El tema de la modernización es un componente importante de la ideología de los dirigentes, sobre todo porque reduce al sinsentido, a la resistencia al cambio, a quien no se conforma a la modernidad. Nunca las relaciones sociales reales, la naturaleza del poder y de la explotación, son ni siquiera evocadas. El objetivo de la nación es asegurar a la elite conquistadora el monopolio del sentido como poder absoluto ${ }^{27}$.

Si la elite dirigente latinoamericana puede ser considerada como un movimiento social que sirve en cada caso nacional como agente del cambio social, significa que se deben precisar sus diferencias respecto del papel de los movimientos sociales en otro tipo de so-

26 HEGEL, G. W. F. Op. Cit., p. 284.

27 TOURAINE, Alain. Las sociedades dependientes: ensayos sobre América Latina. México: Siglo XXI, 1978, p. 25. 
ciedades. El rasgo principal que destaca Touraine a ese propósito y que tiene interés y aplicabilidad en el caso que nos ocupa, hace referencia al carácter heterónomo de los movimiento sociales latinoamericanos, que a diferencia de los países desarrollados, según el esquema clásico de la modernización capitalista, se forman íntimamente ligados al aparato de Estado, hasta convertirlo en el verdadero agente del cambio social ${ }^{28}$. Esa sería la característica fundamental, con la que se ha limitado u obstaculizado de manera deliberada la participación de la sociedad civil en la construcción de alternativas de poder.

En el estudio de los movimientos sociales resulta de vital importancia precisar sus orientaciones culturales, puesto que éstas son inseparables de la forma que adoptan los conflictos internos. En la concepción de Touraine, que tiene amplia aplicación en nuestro análisis, se plantea este aspecto así:

No se trata de añadir un contenido moral a la acción colectiva de la que se supone que su razón de ser es esencialmente de orden económico. La idea de un movimiento social se opone con fuerza a una concepción utilitarista de la acción social colectiva. La idea central que dirige el análisis de una colectividad que pone en vigor un cierto nivel de historicidad, por ejemplo en la modernidad, no es la de un conjunto de valores que penetra en todos los aspectos de la vida social, ni la de una guerra civil incubada, debida a la apropiación de los medios de acción de la sociedad sobre ella misma, bien sean concernientes a la producción económica, el conocimiento o la moral. Una sociedad moderna funciona alrededor de la lucha de sus dirigentes y de los dirigidos por la puesta en acción de la racionalización y la subjetivación. Nada debe separar los valores culturales del conflicto social y el análisis debe resistirse a las ideologías opuestas, las de los dirigentes de la sociedad, que ocultan su poder identificándose con la modernidad y presentando a sus oponentes como simples obstáculos al progreso" 29 .

En ese sentido podemos señalar que una de las principales orientaciones de la cultura moderna, en gestación a lo largo del siglo XIX colombiano como una expresión de la voluntad de poder de un sector de la elite dirigente, adoptó el tema de la educación y la aplicación del conocimiento científico (la técnica) como una de sus principales estrategias para justificar su concepción de la modernización y aproximarse a la adopción de una mentalidad nueva. En ese orden de ideas, el concepto de cultura moderna, o lo que sería equivalente, las orientaciones culturales de tipo laico, operaron en el caso examinado gracias al soporte sobre el pivote de la educación y el conocimiento, como estrategia para ingresar a la modernidad. Quizá sea esa la razón que nos ayuda a comprender por qué se presenta esa confrontación tan fuerte entre diferentes orientaciones culturales, expresada en la lucha por imponer una concepción moral determinada desde la cual orientar la jurisprudencia y la estructuración del Estado, en lo que se constituyó como nuestro kulturkampf (lucha por la cultura).

En lo que resta de este artículo elaboraré un examen de las razones por las que quienes propugnaron por la cultura moderna en la Colombia de la segunda mitad del siglo XIX (liberales radicales), se vieron abocados a una

28 Según A. López Michelsen: "El verdadero creador de riqueza en nuestros países ha sido el Estado”. Introducción al estudio de la Constitución en Colombia. Bogotá: USTA, 1978, p. 12.

29 TOURAINE, Alain. Critique de la modernité. París: Editions A. Fayard, 1992, pp. 279-280 (trad. mía). 
derrota estrepitosa que los marginó del aparato de Estado y los puso en la condición de contestatarios frente a un nuevo grupo hegemónico, con las enormes implicaciones que ya hemos anotado, en el sentido de constituirse en movimientos sociales que trabajan para transformar el modelo de historicidad. Utilizaremos algunos elementos de la teoría de la evolución cultural habermasiana, confrontándola con las observaciones elaboradas por Germán Colmenares en torno a la realidad cultural de Hispanoamérica en el siglo pasado.

\section{Evolución cultural versus convenciones culturales}

La situación cultural de la Colombia del siglo XIX estuvo marcada por el drama de encontrar su propia identidad. En los albores del siglo se sentía el impulso de una nueva época en la que la influencia de la ilustración española y las políticas de los regímenes Borbones obligaban a asimilar la racionalidad de la ciencia útil a los cambios en el aparato productivo y en los sistemas administrativos. A renglón seguido se precipita la crisis de la monarquía española, cuando aparecen con intensidad las reclamaciones de los criollos ilustrados para ser tenidos en cuenta y dejar de ser "ciudadanos de segunda clase". En medio de esas reclamaciones procedieron a buscar modelos de identidad para enfrentarse a la incomprensión de que fueron objeto durante el movimiento juntista en la península Ibérica; los criollos formaron sus propias juntas en las que se buscaba ante todo el nuevo norte en materia de dirección de la acción colectiva y de los patrones de identidad individual.

La lucha contra la herencia española, entendida ahora como un pesado lastre que es necesario abandonar si se quiere formar una nueva realidad, se verá impulsada por la necesidad de crear una conciencia colectiva renovada en la que el legado español sea sometido a un proceso de estigmatización para construir de esa manera una "leyenda negra" en torno al patrimonio cultural hispánico. Este fenómeno, que ya se advierte en las discusiones de la primera etapa de formación de la República, será acentuado por la repulsa que ocasionó el periodo del terror de la reconquista española, cuando se logra unificar la opinión pública en contra del invasor y de las injusticias y atrocidades que cometió. En ese contexto se explica la simpatía creciente por la causa emancipadora y la participación y cuota de heroísmo en la guerra de independencia.

Obtenida la victoria militar y garantizada la independencia formal en el plano político se impuso una tarea de descomunales proporciones, a saber, la construcción de una nueva realidad, la proyección de una "comunidad imaginada" sobre las precarias y arduas condiciones de unas sociedades y unos contextos culturales aparentemente destruidos y sobre los que juzgaron los dirigentes de la elite intelectual y los líderes militares que se podía contar con una especie de tabula rasa. Tal vez sea esa la razón que permita comprender el por qué del desmedido optimismo y la falta de tacto de esos líderes cuando se precipitaron a imponer toda suerte de modelos políticos, militares, económicos y culturales en nuestra realidad. Quizá sea ese también el expediente que ayude a comprender algunas de las rectificaciones notables que se producen en algunos de esos dirigentes, como por ejemplo, la actitud de Simón Bolívar frente al problema religioso y en particular en lo relacionado con la introducción de los textos utilitaristas para la formación de abogados, así como las profundas rectificaciones que se producen en el pensamiento constitucionalista del mismo Bolívar cuando llega a la convicción de que en estas latitudes no se podía empezar la vida republicana con un Estado débil, sino que se ne- 
cesitaba un poder ejecutivo fuerte, hasta los extremos de llegar al autoritarismo como posible medida que permitiera aclimatar las instituciones republicanas.

En ese ambiente vivió Colombia durante toda la primera mitad del siglo XIX, con mayor énfasis en algunas coyunturas históricas en que se exacerbaron los sentimientos o las creencias de algún sector de la población, especialmente cuando, a tenor de alguna discusión sobre el fundamento del ordenamiento político o jurídico, se afectaba lo relacionado con las creencias morales y religiosas más profundas que sirvieron de matriz de nuestra cosmovisión decimonónica.

A mediados de siglo se produce la que a la postre fue una de las mayores transformaciones de nuestro ordenamiento institucional republicano, dado que se establece la delimitación de las dos colectividades políticas tradicionales, en torno a las medidas para el cambio social y a los fundamentos que lo inspiraron. La denominada revolución de medio siglo intentó cambiar, de un solo golpe, la que se consideraba como vetusta y anticuada organización, pretendiendo al mismo tiempo sacudir nuestra vieja mentalidad para disponernos a recibir las nuevas orientaciones occidentales. Sobre ese panorama señala Germán Colmenares:

En la Nueva Granada de mediados del siglo XIX la teoría política se encontra- ba enriquecida por una experiencia ajena, la experiencia francesa, y por consiguiente con una terminología y con unos conceptos perfectamente inadecuados a las condiciones sociales y económicas locales. Esa expresión puramente teórica jugó sin embargo un papel muy importante aun sobre realidades que no servía para definir. Así, el estudio de la influencia francesa en este periodo de nuestra historia debería tener ante todo un carácter semántico. Debería preguntarse por las realidades a las cuales designaba con expresiones que corresponden a otra experiencia histórica. A pesar de este equívoco, las ideas prestadas de Europa constituyeron un instrumento político y no una forma de conciencia atemporal y aséptica $^{30}$.

Ese contenido semántico de que habla Colmenares hace referencia al papel de la concepción del Estado en la cultura occidental. Bertrand Badie señala cómo los modelos occidentales de gobierno se impusieron como modelos universales de una manera tautológica, porque de todas las organizaciones políticas sólo el Estado se autoproclamó como universal, en virtud de asociarse al desarrollo de la Razón y como su propia encarnación:

Construido por referencia directa a la Razón, éste no puede menos que proclamarse universal y sus principios de fun-

30 COLMENARES, G. Partidos políticos y clases sociales. Bogotá: Uniandes, 1968, p. 25. También Colmenares considera que ese proceso de incorporación de ideas europeas trató de convertirse en el soporte para un fallido proceso democratizador, por medio de la educación popular orientada según esos fundamentos conceptuales: "Es cierto, sí, que se adoptó formas europeas en materia de pensamiento político, lo que no resulta extraño si tenemos en cuenta que la casi totalidad de las formas de cultura que se exhibían en Colombia en el siglo XIX era de procedencia europea. Lo que no suele reconocerse voluntariamente a esta generación [se refiere a la generación de medio siglo y a los liberales-radicales] son los esfuerzos que realizó para difundir este tipo de ideología entre las masas. Fue un intento fallido de ‘democratización’ y tenía que serlo porque la universalización del enunciado de tales teorías no podía disimular la oposición feroz que encontraban en formas de conciencia impermeables a la identificación con los intereses de una clase”. Op. Cit., p. 25. 
cionamiento no pueden menos que dirigir sus esfuerzos a reducir la variedad de órdenes políticos que constituyen el orden internacional. A diferencia de las otras posibilidades de organización del poder, una autonomía del espacio público diferenciado de la sociedad civil, el Estado no puede terminar su construcción más que distinguiéndose de lo particular, bien sea que se trate de los intereses privados, de las culturas específicas o de agrupaciones comunitarias ${ }^{31}$.

La construcción del Estado transforma de manera sensible la estructura de la sociedad tradicional, en el sentido de que crea un espacio propio en el que no se reconocen las diferencias comunitarias, y la naturaleza humana queda determinada por la capacidad del Estado para otorgar y reconocer sus derechos. Las implicaciones de este orden de cosas en el plano cultural son muy importantes, pues pasa de ser una expresión de la identidad y la conciencia colectiva a una fórmula de la legitimación política, bajo la forma de cultura política, o, de lo contrario, como lo señala Badie, se convierte simplemente en un producto residual dejado a la curiosidad de los antropólogos ${ }^{32}$.

Esta universalización del modelo estatal occidental configura una realidad histórica en la que entran en pugna la tradición y las nuevas ideas. En esa dirección se movió Mariano Ospina Rodríguez cuando elaboró agudos análisis de la situación social del país en el periodo de la Confederación Granadina. En su discurso de posesión como presidente de la República, el $1^{\circ}$ de abril de 1857 , expresó su pensamiento en los siguientes términos:

Así las instituciones políticas, copiadas de los códigos de otras naciones, no fueron la expresión del estado social, sino que constituyeron un antagonismo completo con las ideas, las convicciones, las preocupaciones, las tendencias, los hábitos y las costumbres del país. A la inversa de casi todas las revoluciones populares, que tienen por objeto poner en armonía las formas políticas con el estado social, la revolución en Nueva Granada, y la de los demás países hispanoamericanos, se hizo para cambiar el estado social, para transformar la nación vaciándola en un molde nuevo. Pero, como una nación no ha cambiado ni cambiará jamás de un día para otro sus convicciones, sus hábitos y su modo de ser, la transformación apetecida no pudo quedar consumada con la promulgación de las nuevas leyes políticas, y el antagonismo ha debido subsistir largo tiempo ${ }^{33}$.

31 BADIE, B. L’État importé. París: Librairie A. Fayard, 1992, p. 68 (trad. mía).

32 "La cultura así mismo ve su status desplazado: de principio de expresión identitario o de conciencia colectiva se convierte bien sea en forma de legitimación del sistema político bajo el apelativo de cultura política, o bien en simple principio residual abandonado a la curiosidad de los antropólogos”. Op. Cit., p. 71.

33 OSPINA, M. "Estado político de la Nueva Granada”. En: Escritos sobre economía y política. Bogotá: Universidad Nacional (Divulgación Cultural), 1969, p. 175. En el mismo discurso anotaba Ospina: “Que una nación sea compelida por la fuerza a cambiar su Constitución Política y a recibir instituciones en pugna con sus exigencias sociales, es un hecho por desgracia demasiado frecuente en la historia de todos los tiempos y de todos los pueblos, más fecundo siempre en conquistas que en actos de emancipación. Pero que un pueblo, movido solamente por la esperanza de regenerarse, adopte instituciones exóticas, en oposición con sus hábitos, con sus preocupaciones y su modo de ser; y que las mantenga constante en medio de las contrariedades y contiendas y luchando hasta consigo mismo, es un fenómeno social tan interesante como extraordinario, y del cual acaso no se encuentre ejemplo en los factores de la especie humana antes del que hoy dan la Nueva Granada y algunos otros Estados hispano-americanos; ejemplo digno de alto aprecio, y que hoy pasa inadvertido pero que algún día tendrá la admiración y el aplauso de la historia” (Ibíd., p. 177). 
Pudieron más las convenciones adoptadas de otros contextos, bajo el supuesto de que de esa manera se estaba entrando en la senda de la historia de la época, sin reconocerse plenamente la capacidad organizativa de lo que era la tradición cultural colombiana de la época. Se intentó desarrollar una instancia relativamente avanzada del pensamiento moral y de la actividad educativa, con el propósito de orientar la vida pública y el ejercicio del poder, combinando también esa tendencia a la “juridización” ${ }^{34}$ con nuevos enfoques acerca de la ciencia del derecho. Todos estos esfuerzos sólo consiguieron dejar el testimonio de una contracultura que propugnaba por el pleno ingreso a la modernidad, con las consecuencias que eso pudiera acarrear en términos de la modernización material.

Quizá se pueda constatar que algo quedó como potencial de aprendizaje de una ética regida por principios diferentes a los del iusnaturalismo clásico, pero se muestra también que el desarrollo cultural del siglo XIX colombiano quedó anclado en una concepción de corte tradicionalista, a la luz de la cual se hicieron algunos avances en el plano de la modernización y se racionalizaron algunas estructuras de la conciencia. Estas constataciones nos ponen de presente el fenómeno según el cual el proceso de aprendizaje y sus correspondientes potenciales, para expresarlo en términos de la concepción de Habermas, se verificaron en esta situación histórica concreta como un convencionalismo que se consideró indispensable para lograr el cometido de un nuevo ordenamiento político y social. En otros términos, la adopción de convenciones culturales foráneas, que fueron en su contexto el fruto de una lenta superación de niveles de evolución cultural, se llevó a cabo en nuestro medio de una forma sobresaltada e improvisada dejando de lado las consideraciones acerca de nuestras propias condiciones culturales. No quiere esto decir que en la experiencia histórica de cada cultura, particularmente de los centros cosmopolitas, se haya verificado un tránsito límpido, prístino e indoloro en el que se hayan obviado los conflictos. En efecto, ese supuesto sería desmentido por la historia particular de cada una de esas experiencias locales, puesto que justamente una de las características distintivas de los procesos históricos es la lucha o la confrontación por el reconocimiento. Otro aspecto diferente es que ese conflicto se genere en el marco de una situación en la que los potenciales de aprendizaje de una sociedad, es decir, sus experiencias colectivas y su acervo de vivencias, permitan el manejo de la confrontación, aspecto éste que parece inevitable a la hora de intentar transformaciones o modificaciones de los marcos institucionales de la vida colectiva.

Aunque extremadamente tradicionalista esta concepción de Ospina, no deja pasar por alto la descoordinación entre realidad cultural e instituciones políticas en el contexto latinoamericano. Esta era una antigua convicción de Ospina, quien en el primer número del periódico La civilización ya lo había expresado de la siguiente manera: "para lo que no estaba preparado este país era para las instituciones políticas que recibió; lo que quiere decir únicamente, que esas instituciones no estaban acordes con las doctrinas, hábitos, costumbres y leyes que regían en el país; y ese acuerdo era necesario para que tuvieran estabilidad y eficacia”. (Ibíd., p. 88). Una situación semejante revela José Victorino Lastarria respecto de la situación chilena: "El sistema colonial se apoyaba en las costumbres y marchaba en íntima unidad y perfecta armonía”. Cf. COLMENARES, G. Las convenciones contra la cultura. Bogotá: Tercer Mundo, 1987, p. 57.

34 Según Habermas “La expresión ‘juridización’ (Verrechtlichung) se refiere, dicho en términos muy generales, a la tendencia que se observa en las sociedades modernas a un aumento del derecho escrito”. Crítica de la razón funcionalista. Vol. II de Teoría de la acción comunicativa. Madrid: Taurus, p. 504. Este autor distingue cuatro "hornadas" de juridización que marcan etapas de desarrollo de la sociedad moderna (Estado burgúes, Estado de derecho, Estado democrático de derecho, Estado social y democrático de derecho). Op. Cit., p. 505. 
Para el caso colombiano, parece ser que en el siglo XIX se presenció una situación excepcional, conformada por la coyuntura internacional de finalización del antiguo régimen y las luchas revolucionarias por el orden republicano, que impactó de una forma definitiva la conciencia de la élite criolla, a tal punto que ésta no vaciló en identificar el destino colectivo de los pueblos de Occidente con la realización de un ideal de humanidad en el que nos debíamos liberar de los yugos y obstáculos a la razón. Esa confianza ilimitada en la razón humana, tan preciada por las corrientes del iluminismo, vendría a tener concreción en forma colectiva en las luchas por el reconocimiento de nuevos actores sociales y de nuevos sujetos históricos en el siglo XIX (el proletariado, los partidos nacionalistas, las elites intelectuales, los industriales, etc.).

La adopción súbita de patrones culturales seculares, entendidos como una alternativa irreversible en el curso de la humanidad, se mezcló con el ideal del progreso, que determina el sendero del siglo pasado hasta convertirse en un motivo central para toda la humanidad. Ya no son solamente los cambios graduales que se puedan presentar en una sociedad determinada, entendidos como una respuesta a nuevas circunstancias, sino que desde entonces esos cambios serán caracterizados y adjetivados de acuerdo a un determinado sentido de la historia: el máximo de racionalidad en el comportamiento de los hombres será calificado como progreso.
La confianza irrestricta en esa forma peculiar de entender la razón humana desconoció u olvidó las aporías a que pudiera llevarnos, y la cultura moderna así entendida, en tanto que proyecto cultural de la modernidad, se elevó altiva por encima de cualquier otra consideración.

De esa confianza irrestricta se valieron nuestros líderes políticos y reformadores sociales de estirpe liberal-radical para avanzar en forma decidida en el camino de la transformación cultural por medio de la educación pública, de manera que ésta sirviera de soporte para los cambios a nivel de la organización político-administrativa y económica. Es cierto que la transformación que se pretendía chocó en los países influenciados decididamente por la cultura católica tradicional con una férrea oposición que impidió cualquier intento de transacción o de diálogo. La doctrina ecuménica de la Iglesia Católica se opuso de una manera frontal a esas nuevas tendencias del mundo moderno, sin constituir durante la mayor parte del siglo XIX una alternativa que respondiera de una forma creativa a las profundas transformaciones operadas en el contexto de la cultura moderna, en la que la influencia del protestantismo había permitido la aclimatación y el desarrollo de una actividad modernizante y una mentalidad moderna. La denominada “doctrina social de la iglesia” se constituyó en una respuesta algo tardía, si se toma en cuenta el avance impresionante alcanzado por las transformaciones seculares ${ }^{35}$.

35 Tratando de explicar la posición de la Iglesia Católica durante el periodo examinado, Jaime Rodríguez, SDB, considera lo siguiente: "Se entiende por qué la posición de la Iglesia fue eminentemente defensiva. Su 'cuestión social' del momento era la defensa de la institución religiosa, de su puesto en la sociedad, de sus valores tan identificados con el ordenamiento social que se desmoronaba y daba paso a formas sociales eminentemente laicistas, con una concepción de autoridad que ya no emanaba de Dios. La iglesia se encerró, entonces, en sí misma y se parapetó en una posición de condenación de las 'cosas nuevas,' el liberalismo, el socialismo, la nueva cultura”. También reconoce este autor que los pronunciamientos de la Iglesia de entonces no fueron sobre la cuestión social, sino sobre la cuestión moral. RODRÍGUEZ, J. Doctrina social de la Iglesia y ciencias sociales. Bogotá: Universidad Nacional, 1992, p. 34. 
El intento de conciliación que inicia la Iglesia Católica a partir del pontificado de León XIII (1878-1903), llega a los Estados Unidos de Colombia en un momento en el que las tendencias tradicionalistas encabezadas por M. A. Caro habían logrado desvertebrar los fundamentos de la legitimidad política de los regímenes liberales-radicales, en particular en lo relacionado con el proyecto de fundar la dimensión normativa de un orden social y cultural de tipo laico, en los planteamientos del utilitarismo y en menor proporción en las doctrinas positivistas. Para finales de la década de 1870 el proyecto liberal-radical estaba derrotado por el proyecto de la Regeneración que promulgaba la necesidad urgente de retornar al cauce original de nuestra cultura -“auxilio de la cultura social” llamaba R. Núñez a las creencias católicas de los colombianos- ${ }^{36}$, para fundamentar desde allí el orden normativo y acompasar las transformaciones materiales o modernizantes con una mentalidad tradicionalista que garantizara el mantenimiento del orden social.

En efecto, se trataba de sustituir una visión extremista por otra, si nos atenemos a las interpretaciones según las cuales quienes pretendieron instaurar una nueva fundamentación del orden republicano en nuestro medio actuaron de una manera irreflexiva, tratando de imponer un nuevo orden simbólico a como diera lugar. En ese sentido es que se habla de "teologías de la república," para significar que los proyectos en contienda no se desprenden de una inclinación por convertir la relación del hombre con el mundo en un discurso en torno a la divinidad; de un lado estaría la teología racional o natural, también llamada por E. Cassirer teología de la Ilustración, de la cual fueron tributarios nuestros republicanos liberales, versus una teología católica ortodoxa, representada en nuestro medio por los tradicionalistas ${ }^{37}$. De la confrontación de estas dos formas teológicas de ver el mundo sólo puede esperarse la incomprensión y la violencia, tanto en el plano simbólico como en el plano material, tal como en efecto lo vivimos en nuestra historia republicana del siglo XIX.

\section{Bibliografía}

BADIE, Bertrand. L'état importé. París: Editions A. Fayard, 1992.

BERGER, Peter. El dosel sagrado. Buenos Aires: Amorrortu, 1971.

BRAUDEL, Fernand. La historia y las ciencias sociales. Madrid: Alianza, 1974.

36 Esta nueva constitución -decía Núñez en el discurso inaugural al consejo nacional de delegatarios que preparó la Constitución Política de 1886-, para que satisfaga la expectativa general, debe en absoluto prescindir de la índole y tendencias características de la que ha desaparecido dejando tras de sí prolongada estela de desgracias. El particularismo enervante debe ser reemplazado por la vigorosa generalidad. Los códigos que funden y definan el derecho deben ser nacionales; y lo mismo la administración pública encargada de hacerlos efectivos. En lugar de un sufragio vertiginoso y fraudulento, deberá establecerse la elección reflexiva y auténtica; y llamándose, en fin, auxilio de la cultura social los sentimientos religiosos, el sistema de educación deberá tener por principio primero la divina enseñanza, por ser ella el alma mater de la civilización del mundo". NÚÑEZ, R. "Mensaje al consejo de delegatarios”. En: La reforma política en Colombia. Bogotá: Imprenta de la Luz, 1884, p. 1250.

37 Alfredo Gómez hace referencia a esta confrontación entre las dos teologías en su artículo "Teologías de la república en el siglo XIX colombiano”. Cuadernos de filosofía latinoamericana, 58-59, 1994. 
CARO, José Eusebio. “Al Sr. Joaquín Mosquera, sobre el principio utilitario enseñado como teoría moral en nuestros colegios, y su relación que hay entre costumbres y moral." La civilización, 10, 1849.

COLMENARES, Germán. Las convenciones contra la cultura. Bogotá: Tercer Mundo, 1987.

. Partidos políticos y clases sociales en Colombia. Bogotá: Uniandes, 1968.

DESPLAND, Michel. "La notion de culture". En: DESPLAND, M., et al. Religión et culture. Québec: PUL-Editions du Cerf, 1986.

ELIADE, Mircea. Mito y realidad. Barcelona: Guadarrama, 1973.

ELIAS, Norbert. El proceso de la civilización: investigaciones sociogenéticas y psicogenéticas. México: F.C.E., 1997.

GÓMEZ, Alfredo. “Teologías de la república en el siglo XIX colombiano.” En: Cuadernos de filosofía latinoamericana, 58-59, 1994.

GONZÁLEZ, Jorge Enrique. Positivismo y tradicionalismo en Colombia. Bogotá: El Búho, 1997.

HABERMAS, Jürgen. Crítica de la razón funcionalista. Vol. II de Teoría de la acción comunicativa. Madrid: Taurus, 1987.

"Derecho y moral (dos lecciones).” En: El derecho, la política y la ética. Comp., David Sobrevilla. México: Siglo XXI/UNAM, 1991.

. El discurso filosófico de la modernidad. Madrid: Taurus, 1989.
Facticidad y validez: sobre el derecho y el Estado democrático de derecho en términos de teoría del discurso. Madrid: Trotta, 1998.

. Perfiles filosófico-políticos. Madrid, Taurus, 1975.

. Problemas de legitimación en el capitalismo tardío. Buenos Aires: Amorrortu, 1975.

. Racionalidad de la acción y racionalización social. Vol. I de Teoría de la acción comunicativa. Madrid: Taurus, 1987.

La reconstrucción del materialismo histórico. Madrid: Taurus, 1981.

HEGEL, Georg W. F. Enciclopedia de las ciencias filosóficas. México: Porrúa, 1973.

LÓPEZ MICHELSEN, Alfonso. Introducción al estudio de la constitución en Colombia. Bogotá: USTA, 1983.

MELO, Jorge O. “Algunas consideraciones globales sobre modernización y modernidad”. En: Colombia: el despertar de la modernidad. Por F. Viviescas y F. Giraldo. Bogotá: Ediciones Foro, 1994.

. "Proceso de modernización en Colombia, 1850-1939”. Revista de extensión cultural (Universidad Nacional de Colombia, sede Medellín) No. 20, 1985.

NÚÑEZ, Rafael. La reforma política en Colombia. Bogotá: Imprenta de la Luz, 1884.

OSPINA RODRÍGUEZ, Mariano. Escritos sobre economía y política. Bogotá: Universidad Nacional de Colombia (Divulgación Cultural), 1969. 
PICÓN SALAS, Mariano. De la conquista a la independencia. Caracas: Monte Ávila Editores, 1978.

RODRÍGUEZ, Jaime, SDB. Doctrina social de la Iglesia y ciencias sociales. Bogotá: Empresa Editorial U.N., 1992.

SERRANO, Enrique. Legitimación y racionalización. México: AnthroposUNAM, 1994.

TOURAINE, Alain. Critique de la modernité. Paris: Librairie A. Fayard, 1992.
Las sociedades dependientes: ensayos sobre América Latina. México: Siglo XXI, 1978.

TROELTSCH, Ernest. El protestantismo y el mundo moderno. México: F.C.E., 1951.

WEBER, Max. Economía y sociedad. México: F.C.E., 1977. 